\title{
Identification of a genome-specific repetitive element in the Gossypium D genome
}

 \\ Xiaoyan Cai ${ }^{2}$, Zhongli Zhou ${ }^{2}$, Xingxing Wang ${ }^{2}$, Yuling Liu ${ }^{4}$, Yanchao Xu ${ }^{2}$, Yuqing Hou ${ }^{2}$, Renhai Peng ${ }^{4}$, Kunbo

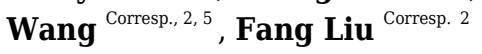 \\ ${ }^{1}$ Gembloux Agro-Bio Tech, University of Liège, Gembloux, Namur, Belgium \\ 2 Research Base of Tarium University, State Key Laboratory of Cotton Biology, Institute of Cotton Research of Chinese Academy of Agricultural Science, \\ Anyang, Henan, China \\ 3 School of Biological and Physical Sciences (SBPS), Jaramogi Oginga Odinga University of Science and Technology (JOOUST), Bondo-Kenya, Bondo, Kenya \\ 4 Anyang Institute of Technology, Anyang, Henan, China \\ 5 Tarium University, Alar, Xinjiang, China \\ Corresponding Authors: Kunbo Wang, Fang Liu \\ Email address: wkbcri@163.com, liufcri@163.com
}

The activity of genome-specific repetitive sequences is the main cause of genome variation between Gossypium A and D genomes. Through comparative analysis of the two genomes, we retrieved a repetitive element termed ICRd motif, which appears frequently in the diploid Gossypium raimondii $\left(D_{5}\right)$ genome but rarely in the diploid Gossypium arboreum $\left(A_{2}\right)$ genome. We further explored the existence of the ICRd motif in chromosomes of G. raimondii, G. arboreum, and two tetraploid (AADD) cotton species, Gossypium hirsutum and Gossypium barbadense, by fluorescence in situ hybridization (FISH), and observed that the ICRd motif exists in the $\mathrm{D}_{5}$ and D-subgenomes but not in the $\mathrm{A}_{2}$ and A-subgenomes. The ICRd motif comprises two components, a variable tandem repeat (TR) region and a conservative sequence (CS). The two constituents each have hundreds of repeats that evenly distribute across 13 chromosomes of the $D_{5}$ genome. The ICRd motif (and its repeats) was revealed as the common conservative region harbored by ancient Long Terminal Repeat Retrotransposons. Identification and investigation of the ICRd motif promotes the study of $A$ and $D$ genome differences, facilitates research on Gossypium genome evolution, and provides assistance to subgenome identification and genome assembling. 


\section{Identification of a genome-specific repetitive element in 2 the Gossypium D genome}

3 Hejun Lu ${ }^{1,2^{*}}$, Xinglei Cui ${ }^{*}$, Yanyan Zhao ${ }^{1}$, Richard Odongo Magwanga ${ }^{1,3}$, Pengcheng $\mathrm{Li}^{1}$, Xiaoyan Cai ${ }^{1}$, 4 Zhongli Zhou ${ }^{1}$, Xingxing Wang ${ }^{1}$, Yuling Liu ${ }^{4}$, Yanchao Xu ${ }^{1}$, Yuqing Hou ${ }^{1}$, Renhai Peng ${ }^{4}$, Kunbo Wang ${ }^{1,5+}$, 5 Fang Liu ${ }^{1+}$

${ }^{1}$ Research Base of Tarium University, State Key Laboratory of Cotton Biology, Institute of Cotton Research of Chinese Academy of Agricultural Science, Anyang, Henan, 455000, China

${ }^{2}$ Gembloux Agro-Bio Tech, University of Liège, Gembloux, 5030, Belgium

${ }^{3}$ School of Biological and Physical Sciences (SBPS), Jaramogi Oginga Odinga University of Science and Technology (JOOUST), P.O Box 210-40601, Bondo-Kenya

${ }^{4}$ Anyang Institute of Technology, Anyang, Henan, 455000, China

${ }^{5}$ Tarium University, Alar, Xinjiang. 843300, China

${ }^{*}$ These authors contributed equally to this work.

+Correspondence: Kunbo Wang, E-mail: wkbcri@163.com; Fang Liu, liufcri@163.com

Abstract: The activity of genome-specific repetitive sequences is the main cause of genome variation between Gossypium A and D genomes. Through comparative analysis of the two genomes, we retrieved a repetitive element termed ICRd motif, which appears frequently in the diploid Gossypium raimondii $\left(\mathrm{D}_{5}\right)$ genome but rarely in the diploid Gossypium arboreum $\left(\mathrm{A}_{2}\right)$ genome. We further explored the existence of the ICRd motif in chromosomes of G. raimondii, G. arboreum, and two tetraploid (AADD) cotton species, Gossypium hirsutum and Gossypium barbadense, by fluorescence in situ hybridization (FISH), and observed that the ICRd motif exists in the $\mathrm{D}_{5}$ and Dsubgenomes but not in the $\mathrm{A}_{2}$ and A-subgenomes. The ICRd motif comprises two components, a variable tandem repeat (TR) region and a conservative sequence (CS). The two constituents each have hundreds of repeats that evenly distribute across 13 chromosomes of the $\mathrm{D}_{5}$ genome. The ICRd motif (and its repeats) was revealed as the common conservative region harbored by ancient Long Terminal Repeat Retrotransposons. Identification and investigation of the ICRd motif promotes the study of A and D genome differences, facilitates research on Gossypium genome evolution, and provides assistance to subgenome identification and genome assembling.

Keywords: Gossypium; cotton plant, D genome; repetitive element; genome-specific; fluorescence in situ hybridization (FISH); evolution

\section{Introduction}

Repetitive DNA sequences are common in eukaryotic genomes, and account for a large fraction of the host genome (Ibarra-Laclette et al., 2013). Their amount is highly correlated with the size of the host genome (Feschotte, 2008). Repetitive DNA is divided into two major groups based on their structures: tandem repeats and interspersed repeats (Jurka et al., 2005). Tandem repeats are known as simple sequence repeat (SSR), and include microsatellites, mini-satellites, and satellites (Jeffreys, et al., 1990). Interspersed repeats are also referred to as transposable elements (TEs) or transposons.

After the first TE of Ac/Ds was reported in maize (McClintock, 1950; Brink \& Williams, 1973; Goldschmidt, 2002), further TEs have been identified in many eukaryotic species (Munoz-Lopez \& Garcia-Perez, 2010). There are thousands of different TE families in plants, which display extreme diversity (Sanmiguel \& Bennetzen, 1998; Bennetzen, 2005; Morgante, 2006). Finnegan first proposed a TE classification system, which includes two classes based on their transposition mechanisms, viz., those mediated by RNA (Retrotransposons) and those by DNA (DNA transposons) (Bowen \& Jordan, 2002; Wessler, 2006; Arkhipova, 2018). Wicker unified TEs nomenclature and classification by applying mechanistic and enzymatic criteria (Wicker et al., 2007). TEs play important roles in the genome through diverse ways, such as variation in intron size (Deutsch \& Long, 1999; Zhang et al., 2011; Koonin, Csuros \& Rogozin, 2013), segmental duplication (Del Pozo \& Ramirez-Parra, 2015), transfer of organelle DNA to the nucleus (Adams \& Palmer, 2003), expansion/contraction of tandem repeats, and illegitimate recombination 
46

47

(Finnegan, 1989; Koike, Nakai \& Takagi, 2002). Long Terminal Repeat Retrotransposons (LTR-TEs), which are usually scattered throughout genomes, are the most abundant TE type and can cause genome expansion over a short evolutionary period particularly in plants (Piegu et al., 2006). The investigation of genome-specific TE is an efficient approach to studying species formation and genome evolution (Dong et al., 2018).

Gossypium, a genus of flowering plants from which cotton is harvested, diverged from the common ancestor with Theobroma cacao approximately 33.7 million years ago (MYA) (Wang et al., 2012). Gossypium comprises eight diploid $(2 n=2 x=26)$ genomic groups: $A, B, C, D, E, F, G, K$, and one allotetraploid $(2 n=4 x=52)$ genomic group: AD (Wang, Wendel \& Hua, 2018). Gossypium species are good subjects for research on polyploidization, genomic organization and genome-size variation because of their high genome diversity: from the smallest New World D genome with an average of $885 \mathrm{Mb}$ to the Australian K-genome with an average of $2576 \mathrm{Mb}$ (Hendrix \& Stewart, 2005). The accumulation of different lineage-specific TEs was thought to be responsible for the variation in genome size in Gossypium genomic groups (Hawkins et al., 2006; Lu et al., 2018). Of the eight genomic groups, the $\mathrm{A}$ and $\mathrm{D}$ groups are the main ones investigated in cotton genomics research (Du et al., 2018). Gossypium hirsutum, the major cultivated cotton species, is known to have originated from the progenitors of G. arboreum $\left(\mathrm{A}_{2}\right)$ and $G$. raimondii $\left(\mathrm{D}_{5}\right)$ (Paterson et al., 2012). The key phenotype difference between G. arboreum and G. raimondii is the production of spinnable fibers in the former but not the latter. In terms of the genomics, the former has a genome size of $1,746 \mathrm{Mb} / 1 \mathrm{C}$, which is about two times that of the latter $(885 \mathrm{Mb} / 1 \mathrm{C})$ (Hendrix \& Stewart, 2005). Genome sequencing showed that the difference in the numbers of protein-coding genes between the A $(41,330)$ and D $(37,505)$ genomes is not obvious, while the lineage-specific TE content is the main reason for the size gap between the A and D genome (Li et al., 2015; Du et al., 2018). Moreover, Wang, Huang \& Zhu (2016) suggested that the transposable elements play an important role during cotton genome evolution and fiber cell development. Thus, research on the lineage-specific repetitive sequences between $\mathrm{A}$ and $\mathrm{D}$ genomes is a meaningful path to investigate speciation dynamics.

Fluorescence in situ hybridization (FISH) is a versatile tool to visualize the distribution of certain DNA sequences in chromosomes and plays a vital role in cytogenetic research. In tetraploid cotton, FISH has played a key role in cytological experiments that have contributed to the understanding the allotetraploid event. FISH with DNA segments harboring dispersed repeats has identified genome-specific repeats between the A and D genome, and showed that some A genome repeats appear to have spread to the D genome (Hanson, Zhao et al. 1998; Zhao, Si et al., 1998). Although the repetitive DNA fragments are more common in the A than in the D genome, one tandem repeat family (B77) has been well-characterized from the D Chromosome (Zhao, Ji et al. 1998). Recently, more repetitive sequences were observed with FISH in the cotton genome after construction of a cotton cytogenetic map (Cui, Liu et al., 2015; Liu, Peng et al., 2016). Lu et al. (2018) suggested that CICR was an important contributor to the size gap between the A and D genome. The identification and localization of these repetitive sequences benefit genome assembly and facilitate understanding of the mechanism of genome evolution.

The D genomic group represents a diverse group of diploids that diverged from a branch of A, B, C, E, F, G, and K genomic groups about 5-10 MYA (Senchina et al., 2003). Although the D genome has the smallest size of all Gossypium species, this study has revealed the presence of a set of repeat elements with high proliferation, which is absent in the A genome. The discovery and characterization of these novel repetitive elements provides components for a repetitive sequences database and new insight into Gossypium evolution.

\section{Materials and methods}

\subsection{Plant materials}

Cotton plants were obtained from the National Wild Cotton Nursery in Hainan Island, China, sponsored by the Institute of Cotton Research of Chinese Academy of Agricultural Sciences (ICR-CAAS). They were also conserved in the greenhouse at ICR-CAAS' headquarters in Anyang City, Henan Province, China. The DNA and cells came from specimens listed in Table 1, which is based on the latest nomenclature of Gossypium species (Wang, Wendel \& Hua, 2018). 
The repeat elements were characterized in the G. raimondii genome (Paterson et al., 2012), and compared to genomes in other Gossypium genomes, viz., G. arboreum (Li, Fan et al. 2014), G. hirsutum (AD) (BGI (Li, Fan et al., 2015), NBI (Zhang, Hu et al., 2015), HAU (Wang, Tu et al., 2019), ZJU (Hu, Chen et al., 2019)), G. barbadense $(\mathrm{AD})_{2}$ (HAUv1 (Yuan et al., 2015), CAS (Liu et al., 2015), HAUv2 (Wang, Tu et al., 2019), and ZJU (Hu, Chen et al., 2019)). All genome data was downloaded from Cottongen (https://www.cottongen.org/), except the (AD) ${ }_{2}$-CAS which was obtained from GenBank under PRJNA251673.

\subsection{Characterization of the repetitive element and bioinformatics analysis}

BLASTN (v2.6.0) (Camacho, Coulouris et al., 2009) was used to identify repeat elements in the genomes of the plant material, and in the genomes stored in the databases. We used a threshold of greater than or equal to $80 \%$ matching ratio and an $80 \%$ similarity following the $80-80$ rule suggested by Wicker et al. (2007). The tandem repeats (TRs) were identified with Tandem Repeats Finder (v4.09) (Benson, 1999). We used Perl script for batch extracting sequences from the genome (Doc. S1). Sequence alignments were obtained from MUSCLE (v3.81) (Edgar, 2004). The Unipro UGENE (v1.31) was used to present the alignments and train consensus sequences (Okonechnikovet al. 2012). The inner enzyme annotation was obtained by online CD-search in NCBI (MarchlerBauer et al., 2017). GIRI Repbase (Chen et al., 2007) were queried for annotation. RepeatMasker (v4.07) was used to annotate the insertions and estimate the proportion of repetitive sequences in genomes (http://www.repeatmasker.org).

Flanking LTRs of LTR-TEs were identified with LTRharvest (v1.5.8) (Ellinghaus, Kurtz \& Willhoeft, 2008). Subsequently, Vmatch (v2.3.0) was used to cluster the LTRs (Kurtz, 2003). The divergence time of the LTR-TEs was estimated using the formula $\mathrm{T}=\mathrm{d} / 2 \mathrm{r}$, where $\mathrm{r}$ represents a substitution rate of $1.3 \times 10^{-8}$ per site per year (Ma \& Bennetzen, 2004), and d represents the distances of paired LTRs, which was calculated based on the Kimura twoparameter (Kimura, 1980). The insertions of the repeat elements were obtained based on the BLASTN result, and the LTR-TE and Coding sequence (CDS) information was obtained from genome annotation (Paterson et al., 2012), which were illustrated by the ggplot $2 \mathrm{R}$ package (Wickham 2016) with a sliding $500 \mathrm{~kb}$ window for LTR-TE and CDS. The synteny blocks of the homologous segments were shown by a Perl script (Doc. S1) based on the BLASTN results.

\subsection{Fluorescence in situ hybridization (FISH)}

A probe was designed with the PCR product of the ICRd motif, which was obtained from the forward primer: TTCTATTTTATCCATCGTTATG, reverse: GGAGATAGGATTTGTTGCT; and followed the amplification procedure: firstly, $95^{\circ} \mathrm{C}$ for $5 \mathrm{~min}$ of pre-degeneration; then, 30 cycles at $95^{\circ} \mathrm{C}$ for $30 \mathrm{~s}, 52^{\circ} \mathrm{C}$ for $30 \mathrm{~s}$, and $72^{\circ} \mathrm{C}$ for $2 \mathrm{~min}$. The final extension was done at $72^{\circ} \mathrm{C}$ for $6 \mathrm{~min}$. Composition of the reaction mix used the following: gDNA $(\sim 5 \mu \mathrm{g} / \mathrm{ml})$, primers $(\sim 0.8 \mu \mathrm{M})$, PCR Master Mix (Thermo), and $\mathrm{H}_{2} \mathrm{O}$. The gDNA was extracted from the leaves of the cotton plants (Table 1). The probe was purified and labeled with digoxigenin-dUTP via nick translation, according to manufacturer's instructions (Roche Diagnostics, USA). Mitotic chromosome preparation and FISH procedures were conducted using a modified protocol (Wang et al., 2001).

\section{Results}

\subsection{One specific repetitive sequence in the Gossypium $\mathrm{D}_{5}$ genome}

We performed BLAST to query all of the interspersed repetitive sequences of G. raimondii (Paterson et al., 2012) with the whole genome of G. arboreum $\left(\mathrm{A}_{2}\right)$ (Li et al., 2014). One segment in the G. raimondii $\left(\mathrm{D}_{5}\right)$ genome (Chr05: 50639971-50641791) was filtered out and recognized as $\mathrm{D}_{5}$ genome-specific. This sequence repeats frequently and is spread over 13 chromosomes of the $\mathrm{D}_{5}$ genome (Supplementary Table 1), while it is absent from the $\mathrm{A}_{2}$ genome. Searches in Repbase (Chen et al., 2007) and NCBI found no related annotation and LTRharvest (Ellinghaus, Kurtz \& Willhoeft, 2008) and a CD-search (Marchler-Bauer et al., 2017) revealed it is neither LTR nor a coding sequence. 
136

137

138

139

140

141

142

143

144

145

146

147

148

149

150

151

152

153

154

155

156

157

158

159

160

161

162

163

164

165

166

167

168

169

170

171

172

173

174

175

176

177

178

179

180

Manual inspection revealed the structure of the genome-specific sequence as having two constituents: a tandem repeats array (referred as TR hereafter) composed of 133 bp basic units, and an unknown conservative sequence (referred as CS hereafter) (Figure 1). Based on this feature, we identified 72 sequences in total from the $\mathrm{D}_{5}$ genome with RepeatMasker (Supplementary Table 2), referred to here as the ICRd motif following our previous work (Lu et al., 2018). Among the 72 ICRd motifs, the TRs are length-variable having 2-20 times of basic units (Figure 2a), while the CSs are stable and have an average size $\sim 860 \mathrm{bp}$.

To verify the genome specificity and chromosome distribution of the ICRd motif, we used the PCR product of the ICRd motif from $G$. raimondii to design the probe for FISH on the mitotic chromosomes of diploid $\mathrm{A}_{2}$ and $\mathrm{D}_{5}$, and tetraploid $G$. hirsutum $\left((\mathrm{AD})_{1}\right)$ and $G$. barbadense $\left((\mathrm{AD})_{2}\right)$. The probe generated bright signals covering all the chromosomes of the $\mathrm{D}_{5}$ and $\mathrm{D}$-subgenome, but no signals on the $\mathrm{A}_{2}$ and A-subgenome (Figure 3). These cytogenetic inspections were in accordance with the genomic comparative analysis and further revealed that the ICR $d$ motif is a genome-specific and highly repetitive element in the $\mathrm{D}_{5}$ genome, as well as in the D-subgenome of tetraploid cotton.

\subsection{LTR-TEs inserted with the ICRd motif}

We compared the insertion loci of 72 ICRd motifs with the whole genome repeats annotation (gff file) of the $\mathrm{D}_{5}$ genome (Paterson et al., 2012) and found that each of the motifs is one-to-one harbored within the 72 LTR-TEs (Supplementary Table 3), which meant the former is the inner part of the latter.

We extracted the 72 LTR-TEs sequences from the $\mathrm{D}_{5}$ genome and parsed their structure, which showed all sequences are incomplete, lacking either enzyme or flanking LTRs, the required elements for an intact LTR-TE (Wicker et al., 2007). A consensus accumulation histogram obtained from aligning all of these LTR-TEs together (Supplementary Figure 1) showed these TEs to have a vast sequence variation and a single conservative region representing the insertion region of the ICRd motif (Figure 4). The ICRd motif appears to be more stable than other parts of the TEs along with degradation and evolution. This stability implies the importance of ICRd motif to the TEs.

Of the 72 LTR-TEs, 25 were identified as having paired flanking LTRs, and were used to represent the classification and evolution of these TEs. The LTR cluster results showed that, except for two TEs having similar LTR regions, the other 23 TEs are totally different from each other, indicating that they do not belong to the same family based on the LTR similarity rules (Wicker et al., 2007). The estimated active date curve of these TEs almost all prior to 10 MYA and peaking at 30 MYA (Figure 5) - shows the peak is close to the time that $G$. raimondii and T. cacao diverged approximately 33.7 MYA (Wang et al., 2012), far earlier than the putative divergence time of the Gossypium A and D genomes (Wendel \& Cronn, 2001). These results indicate that these LTR-TEs are ancient and potentially contributed to speciation of Gossypium.

\subsection{Abundant constituents of the ICRd motif in the $\mathrm{D}_{5}$ genome}

To further analyze the genomic features of the ICRd motif, we separately investigated the content and distribution of its two constituents (TR and CS) in the $\mathrm{D}_{5}$ genome (Figure 6a). In total $350 T R$ insertions were detected (Supplementary Table 2). Insertions varied in length (due to the unit repeating at different times) between 2-21, but mainly 2-10 times the basic unit length (Figure $2 b)$. The longest TR insertion in $\mathrm{D}_{5}\left(\mathrm{D}_{5} 03\right.$ : $25689303-$ 25697234) was an extraordinary 61 units up to $8 \mathrm{~kb}$; how it was formed is unknown. On the other hand, a total of 463 CSs were found (Supplementary Table 2). Combining the analyses of the insertion loci of the two constituents, we found 72 TRs and 72 CSs constituting the ICRd motifs (Figure 1).

Further analysis showed that the TR and CS were evenly distributed on the chromosomes based on an $\chi^{2}$ test, with the number of insertions being proportional to the size of the chromosome [TR insertions, $\chi^{2}=5.56(\mathrm{df}=12, \mathrm{P}$ $>0.9)$; CS insertions, $\chi 2=9.08(\mathrm{df}=12, \mathrm{P}>0.5)]$. The even distributions meant that the CS and $T R$ are possible ancient repetitive sequences that have evolved along with the chromosomes. Previous G. raimondii genome sequencing work reported that most TEs in G. raimondii are deletion derivatives lacking the domains that are typically necessary for transposition and that only 3\% of LTR base pairs derived from full-length LTR-TEs

Peer) reviewing PDF | (2019:06:38434:3:0:NEW 11 Nov 2019) 
181 (Paterson et al., 2012). We show that hundreds of constituents of the ICRd motif in $\mathrm{D}_{5}$ are potentially the fragments 182 produced from the ancient LTR-TEs.

\section{3.4 Disappearance of the ICRd motif from Gossypium}

Aiming to observe the disappearance of the ICRd motif in the newly formed Gossypium A genome, we selected two homologous segments from the highly collinear Chromosome 1 of G. raimondii $\left(\mathrm{D}_{5} 01\right)$ and $G$. arboreum $\left(\mathrm{A}_{2} 01\right)$ (Li et al., 2014), respectively. The segment from Chromosome 1 of G. raimondii $\left(\mathrm{D}_{5} 01\right)$ harbored one ICRd motif and its homologous segment from $\mathrm{A}_{2} 01$ was obtained from homologous SSR markers (Supplementary Table 4). The illustration of the syntenic block of the two segments showed that the ICRd motif together with its host LTR-TE were lost on the $\mathrm{A}_{2} 01$ segment, while their up- and downstream conservative regions remained (Figure 7). In the upstream, we observed two insertions rich in repeat sequences especially on the $\mathrm{A}_{2} 01$ segment (Supplementary Table 4), which was potentially due to a recent TE expanding event happening in the A genome ( $\mathrm{Lu}$ et al., 2018). Thus, we observed that the ICRd motifs and host LTR-TEs were lost from the genome with the recent formation of the A genome (Wendel \& Cronn, 2001; Wendel, Flagel \& Adams, 2012), but remained in the $\mathrm{D}$ genome despite mass damage accumulation.

\subsection{Distributions of ICRd motifs in tetraploid cotton}

Tetraploid cotton, G. hirsutum and G. barbadense, are the major cultivated fiber-producing cotton species. Research on the genome of these two species is an important approach to improving cotton yield and quality. However, due to the large number of homologous segments between A and D-subgenomes, the tetraploid cotton genome assemblage has been a great challenge to molecular geneticists (Bowers et al., 2003; Chen et al., 2007b). Through high-throughput sequencing methods, two versions of the $G$. hirsutum genome assembly ((AD) $)_{1}$-BGI (Li et al., 2015), (AD) $)_{1}$-NBI (Zhang et al., 2015)), and two G. barbadense versions (AD) $)_{2}$-HAU (Yuan et al., 2015) and $(\mathrm{AD})_{2}$-CAS (Liu et al., 2015)) were completed in 2015. With the advance of sequencing techniques, the tetraploid genome assemblies were improved in quality (Hu, Chen et al., 2019, Wang, Tu et al., 2019). However, to benefit research in the post-genome era, such as facilitating molecular breeding of cotton, suitable evaluation is needed to provide accurate reference data. Application of the lineage-specific repetitive element and the ICRd motifs are important tools in evaluating the quality of the genome assembly of tetraploid cotton.

To observe the assembling quality of the ICRd motif in tetraploid genomes, we queried it with BLAST in all published tetraploid cotton genomes, including four versions of $G$. hirsutum ((AD) $)_{1}$ ) and four versions of $G$. barbadense $\left((\mathrm{AD})_{2}\right)$ (Table 2). In the case of $(\mathrm{AD})_{1}$, the two recently published (Hu, Chen et al. 2019; Wang, Tu et al. 2019) versions and the previous NBI version were in agreement with our FISH inspection results, viz., that the ICRd motifs only generated the signals on the $\mathrm{D}$-subgenome chromosomes (Figure 3 ). However, the $\mathrm{BGI}$ version ( $\mathrm{Li}$ et al. 2015) is inconsistent with the FISH results in that the ICRd motif was misassembled into the A-subgenome. For the (AD) $)_{2}$ assemblies, the two newly published (Hu, Chen et al. 2019; Wang, Tu et al. 2019) and CAS versions were better assembled than the HAUv1 version. The HAUv1 showed the number of matches in the chromosomeunassembled scaffolds, while the HAUv2 has improved quality (Supplementary Table 5). This means that with advances in genome sequencing techniques, tetraploid genomes can be more precisely assembled though the existence of homologous segments from At and Dt.

\section{Discussion}

\subsection{Identification of ICRd motif and Gossypium evolution}

TEs have played an important function in Gossypium speciation and the accumulation of different genomicspecific TEs were thought to be responsible for genome-size variation in Gossypium (Hawkins et al., 2006). Through FISH inspection, some A genome-specific repetitive elements have been well identified and characterized (Liu et al., 2016), but similar work in the D genome have been rare; this may be because the genome-specific repetitive sequences in the A genome are much more numerous than in the D genome (Liu et al., 2018). However, in 
225

226

227

228

229

230

231

232

233

234

235

236

237

238

the present study, starting with comparative genomic data, we have screened out one kind of specific sequence in the D genome, and subsequently, we have identified and characterized TEs.

The TEs harboring the ICRd motif showed an ancient active date of much earlier than 10 MYA, while the time of divergence of the A and D genomes from the common ancestor is estimated to have occurred 5-10 MYA (Grover et al., 2004). Thus the ICRd motifs have existed in the ancestor of A and D genome, while disappeared along with the formation of the A genome. Previous researchers have considered that the accumulation of lineage-specific TEs, which is thought to be responsible for the variation of Gossypium genomes (Hawkins et al., 2006), and the LTR-TE activities after 5 MYA mainly contributed to the two-fold size difference of the A and D genomes (Zhang et al., 2015). Based on our analysis, we presumed that as in the activity of new repetitive sequences the extinction of ancient repetitive sequences, such as the disappearance of the ICRd motif in the A genome, also contributed significantly to genome evolution. Through FISH, we observed that the ICRd motifs were only distributed in Dsubgenome chromosomes, and the results were in agreement with a previous study which reported that the TE have proliferated in the progenitor genomes but were retained after allopolyploid formation in the D-subgenome (Zhang et al., 2015).

\subsection{ICRd motif support cytogenetic markers for tetraploid cotton}

The identification of the ICRd motif provides a new subgenome marker for the accurate assembling of tetraploid cotton (Chen et al., 2007). Chromosome identification is the foundation of plant genetics, evolution and genomics research (Saranga, 2007; Xie et al., 2012). Although many species have been sequenced, the rapid identification of the subgenome is still useful in applied research. FISH has been used as a reliable cytological technique for chromosome identification in many species (Wang, Guo \& Zhang, 2007), but has only been used recently for the identification of cotton chromosomes (Gan et al., 2012). In the present study, the identified ICRd motifs can be used as a new cytological marker in Gossypium, especially in tetraploids. Further, the repetitive sequence probes are easier and more successfully detected than other probes. Several similar markers have been reported (Liu et al., 2016). The addition of these new cytological markers will enrich the marker database for chromosome identification and facilitate cotton genomic studies.

Eukaryotic genomes have a high proportion of TEs and these TEs make eukaryotic genome assembly much more difficult than simple genome assembly (Treangen \& Salzberg, 2012). Many reported genome sequences have gaps because of the high proportion of TEs (Adams et al., 2000). Allopolyploid genomes are especially difficult to assemble homologous fragments from subgenomes (Chen et al., 2007). Incorrect assembling of the genomes leads to ambiguity in research which, in turn, produces biases and errors when interpreting results (Adams et al., 2000). The repetitive sequences analysis in this work were screened out from the whole genome comparison, we characterize the distribution feature on referenced genome assembly, moreover, FISH observation on chromosomes of somatic cell verified the lineage-specific feature. Combining FISH with genome-specific repeat segments is a convenient and practical approach to observe chromosome differences, in addition to assisting polyploid genome assembling, and evaluating assembling accuracy. With the progress of genome sequencing and assembling, genome assembly will become increasingly more precise and convincing, and it is likely that the latter published tetraploid genome will adopt the BioNano and Hi-C approaches (Hu, Chen et al., 2019, Wang, Tu et al., 2019) and improve the identification of homologous segments from subgenomes. The improved tetraploid cotton genome assemblies were consistent with FISH, which provides a reference for researchers deciding which genomes to adopt in their research.

\section{Conclusions}

We identified and characterized a new type of repetitive sequence termed ICRd motif in the Gossypium D genome. The motifs are interspersed in 13 chromosomes of the D genome, but absent in the A genome, and retained in D-subgenome in tetraploid cotton. We analyzed their structure, genomic distribution, affiliation, and evolution, which revealed a conserved region harbored in ancient LTR-TEs. The identification and characterization of the ICRd motif provided new insight into understanding TE evolution along with the formation of cotton genomes as well as providing a convenient and practical tool to distinguish the A and D genome subsets of the tetraploid cotton

Peer) reviewing PDF | (2019:06:38434:3:0:NEW 11 Nov 2019) 
271

272

273

274

275

276

277

278

279

280

281

282

283

284

285

286

287

288

289

290

291

292

293

294

295

296

297

298

299

300

301

302

303

304

305

306

307

308

309

310

311

312

genome assembly. The ICRd motif has a novel structure and affiliation; how the structure was formed and what function the ICR $d$ motif plays in LTR-TEs would be valuable areas for future research.

Supplementary materials:, Figure S1: Supplementary Figure 1. The whole alignment of the 72 LTR-TEs, Table S1: Blast of the $1.8 \mathrm{~kb}$ sequences in G. raimondii genome, Table S2: The ICRd motifs and their constituents, Table S3: The structures of the LTR-TEs harboring the ICRd motif, Table S4: Information on the two homologous segments, Table S5: Blast results of the ICRd motif with tetraploid cotton.

Acknowledgments: We are indebted to Dr Syed Shan-e-Ali Zaidi of the University of Liège, Belgium, for his guidance in analysis and interpretation of the data

\section{References}

Adams MD, Celniker SE, Holt RA, Evans CA, Gocayne JD, Amanatides PG, Scherer SE, Li PW, Hoskins RA, Galle RF, George RA, Lewis SE, Richards S, Ashburner M, Henderson SN, Sutton GG, Wortman JR, Yandell MD, Zhang Q, Chen LX, Brandon RC, Rogers YHC, Blazej RG, Champe M, Pfeiffer BD, Wan KH, Doyle C, Baxter EG, Helt G, Nelson CR, Gabor Miklos GL, Abril JF, Agbayani A, An HJ, Andrews-Pfannkoch C, Baldwin D, Ballew RM, Basu A, Baxendale J, Bayraktaroglu L, Beasley EM, Beeson KY, Benos P V., Berman BP, Bhandari D, Bolshakov S, Borkova D, Botchan MR, Bouck J, Brokstein P, Brottier P, Burtis KC, Busam DA, Butler H, Cadieu E, Center A, Chandra I, Michael Cherry J, Cawley S, Dahlke C, Davenport LB, Davies P, de Pablos B, Delcher A, Deng Z, Deslattes Mays A, Dew I, Dietz SM, Dodson K, Doup LE, Downes M, Dugan-Rocha S, Dunkov BC, Dunn P, Durbin KJ, Evangelista CC, Ferraz C, Ferriera S, Fleischmann W, Fosler C, Gabrielian AE, Garg NS, Gelbart WM, Glasser K, Glodek A, Gong F, Harley Gorrell J, Gu Z, Guan P, Harris M, Harris NL, Harvey D, Heiman TJ, Hernandez JR, Houck J, Hostin D, Houston KA, Howland TJ, Wei MH, Ibegwam C, Jalali M, Kalush F, Karpen GH, Ke Z, Kennison JA, Ketchum KA, Kimmel BE, Kodira CD, Kraft C, Kravitz S, Kulp D, Lai Z, Lasko P, Lei Y, Levitsky AA, Li J, Li Z, Liang Y, Lin X, Liu X, Mattei B, McIntosh TC, McLeod MP, McPherson D, Merkulov G, Milshina N V., Mobarry C, Morris J, Moshrefi A, Mount SM, Moy M, Murphy B, Murphy L, Muzny DM, Nelson DL, Nelson DR, Nelson KA, Nixon K, Nusskern DR, Pacleb JM, Palazzolo M, Pittman GS, Pan S, Pollard J, Puri V, Reese MG, Reinert K, Remington K, Saunders RDC, Scheeler F, Shen H, Christopher Shue B, SidenKiamos I, Simpson M, Skupski MP, Smith T, Spier E, Spradling AC, Stapleton M, Strong R, Sun E, Svirskas R, Tector C, Turner R, Venter E, Wang AH, Wang X, Wang ZY, Wassarman DA, Weinstock GM, Weissenbach J, Williams SM, Woodage T, Worley KC, Wu D, Yang S, Alison Yao Q, Ye J, Yeh RF, Zaveri JS, Zhan M, Zhang G, Zhao Q, Zheng L, Zheng XH, Zhong FN, Zhong W, Zhou X, Zhu S, Zhu X, Smith HO, Gibbs RA, Myers EW, Rubin GM, Craig Venter J. 2000. The genome sequence of Drosophila melanogaster. Science 287:2185-2195. DOI: 10.1126/science.287.5461.2185.

Adams KL, Palmer JD. 2003. Evolution of mitochondrial gene content: gene loss and transfer to the nucleus. Molecular phylogenetics and evolution 29:380-95.

Arkhipova IR. 2018. Neutral theory, transposable elements, and eukaryotic genome evolution. Molecular Biology and Evolution 35:1332-1337. DOI: 10.1093/molbev/msy083.

Bennetzen JL. 2005. Transposable elements, gene creation and genome rearrangement in flowering plants. Current Opinion in Genetics and Development 15:621-627. DOI: 10.1016/j.gde.2005.09.010.

Benson G. 1999. Tandem repeats finder: A program to analyze DNA sequences. Nucleic Acids Research 27:573580. DOI: $10.1093 /$ nar/27.2.573.

Bowen NJ, Jordan IK. 2002. Transposable elements and the evolution of eukaryotic complexity. Current Issues in Molecular Biology 4:65-76.

Peer) reviewing PDF | (2019:06:38434:3:0:NEW 11 Nov 2019) 
313 Bowers JE, Chapman BA, Rong J, Paterson AH. 2003. Unravelling angiosperm genome evolution by phylogenetic analysis of chromosomal duplication events. Nature 422:433-438. DOI: 10.1038/nature01521.

315 Brink RA, Williams E. 1973. Mutable R-navajo alleles of cyclic origin in maize. Genetics 73:273-296.

316 Camacho, C., G. Coulouris, V. Avagyan, N. Ma, J. Papadopoulos, K. Bealer and T. L. Madden (2009). "BLAST+: architecture and applications." BMC bioinformatics 10(1): 421. DOI: 10.1186/1471-2105-10-421.

Chen ZJ, Scheffler BE, Dennis E, Triplett BA, Zhang T, Guo W, Chen X, Stelly DM, Rabinowicz PD, Town CD, Arioli T, Brubaker C, Cantrell RG, Lacape J-M, Ulloa M, Chee P, Gingle AR, Haigler CH, Percy R, Saha S, Wilkins T, Wright RJ, Van Deynze A, Zhu Y, Yu S, Abdurakhmonov I, Katageri I, Kumar PA, Mehboob-urRahman, Zafar Y, Yu JZ, Kohel RJ, Wendel JF, Paterson AH. 2007. Toward Sequencing Cotton (Gossypium) Genomes. Plant Physiology 145:1303-1310. DOI: 10.1104/pp.107.107672.

Del Pozo JC, Ramirez-Parra E. 2015. Whole genome duplications in plants: An overview from Arabidopsis. Journal of Experimental Botany 66:6991-7003. DOI: 10.1093/jxb/erv432.

325

326

327

328

329

330

331

332

333

334

335

336

337

338

339

340

341

342

343

344

345

346

347

348

Deutsch M, Long M. 1999. Intron-exon structures of eukaryotic model organisms. Nucleic Acids Research 27:32193228. DOI: $10.1093 /$ nar/27.15.3219.

Dong G, Shen J, Zhang Q, Wang J, Yu Q, Ming R, Wang K, Zhang J. 2018. Development and Applications of Chromosome-Specific Cytogenetic BAC-FISH Probes in S. spontaneum. Frontiers in Plant Science 9. DOI: 10.3389/fpls.2018.00218.

Du X, Huang G, He S, Yang Z, Sun G, Ma X, Li N, Zhang X, Sun J, Liu M, Jia Y, Pan Z, Gong W, Liu Z, Zhu H, Ma L, Liu F, Yang D, Wang F, Fan W, Gong Q, Peng Z, Wang L, Wang X, Xu S, Shang H, Lu C, Zheng H, Huang S, Lin T, Zhu Y, Li F. 2018. Resequencing of 243 diploid cotton accessions based on an updated A genome identifies the genetic basis of key agronomic traits. Nature Genetics 50:796-802. DOI: 10.1038/s41588-018-0116-X.

Edgar RC. 2004. MUSCLE: multiple sequence alignment with high accuracy and high throughput. Nucleic acids research 32:1792-7. DOI: 10.1093/nar/gkh340.

Ellinghaus D, Kurtz S, Willhoeft U. 2008. LTRharvest, an efficient and flexible software for de novo detection of LTR retrotransposons. BMC Bioinformatics 9. DOI: 10.1186/1471-2105-9-18.

Feschotte C. 2008. Transposable elements and the evolution of regulatory networks. Nature reviews. Genetics 9:397-405. DOI: $10.1038 / \mathrm{nrg} 2337$.

Finnegan DJ. 1989. Eukaryotic transposable elements and genome evolution. Trends in Genetics 5:103-107. DOI: 10.1016/0168-9525(89)90039-5.

Gan Y, Liu F, Peng R, Wang C, Li S, Zhang X, Wang Y, Wang K. 2012. Individual chromosome identification, chromosomal collinearity and genetic-physical integrated map in Gossypium darwinii and four D genome cotton species revealed by BAC-FISH. Genes \& genetic systems 87:233-41. DOI: 10.1266/ggs.87.233.

Goldschmidt RB. 2002. Marginalia to McClintock's Work on Mutable Loci in Maize. The American Naturalist 84:437-455. DOI: $10.1086 / 281640$.

Grover CE, Kim HR, Wing RA, Paterson AH, Wendel JF. 2004. Incongruent patterns of local and global genome 
size evolution in cotton. Genome Research 14:1474-1482. DOI: 10.1101/gr.2673204.

350

351

352

353

354

355

356

357

358

359

360

361

362

363

364

365

366

367

368

369

370

371

372

373

374

375

376

377

378

379

380

381

382

383

384

385

386
Hanson, R. E., X. p. Zhao, M. N. Islam - Faridi, A. H. Paterson, M. S. Zwick, C. F. Crane, T. D. McKnight, D. M. Stelly and H. J. J. A. J. o. B. Price (1998). "Evolution of interspersed repetitive elements in Gossypium (Malvaceae)." 85(10): 1364-1368. DOI: 10.2307/2446394.

Hawkins JS, Kim HR, Nason JD, Wing RA, Wendel JF. 2006. Differential lineage-specific amplification of transposable elements is responsible for genome size variation in Gossypium. Genome Research 16:12521261. DOI: $10.1101 /$ gr.5282906.

Hendrix B, Stewart JM. 2005. Estimation of the nuclear DNA content of Gossypium species. Annals of Botany 95:789-797. DOI: 10.1093/aob/mci078.

Hu, Y., J. Chen, L. Fang, Z. Zhang, W. Ma, Y. Niu, L. Ju, J. Deng, T. Zhao, J. Lian, K. Baruch, D. Fang, X. Liu, Y. L. Ruan, M. U. Rahman, J. Han, K. Wang, Q. Wang, H. Wu, G. Mei, Y. Zang, Z. Han, C. Xu, W. Shen, D. Yang, Z. Si, F. Dai, L. Zou, F. Huang, Y. Bai, Y. Zhang, A. Brodt, H. Ben-Hamo, X. Zhu, B. Zhou, X. Guan, S. Zhu, X. Chen and T. Zhang (2019). "Gossypium barbadense and Gossypium hirsutum genomes provide insights into the origin and evolution of allotetraploid cotton." Nat Genet 51(4): 739-748. DOI: 10.1038/s41588-019-0371-5.

Ibarra-Laclette E, Lyons E, Hernández-Guzmán G, Pérez-Torres CA, Carretero-Paulet L, Chang TH, Lan T, Welch AJ, Juárez MJA, Simpson J, Fernández-Cortés A, Arteaga-Vázquez M, Góngora-Castillo E, AcevedoHernández G, Schuster SC, Himmelbauer H, Minoche AE, Xu S, Lynch M, Oropeza-Aburto A, CervantesPérez SA, De Jesús Ortega-Estrada M, Cervantes-Luevano JI, Michael TP, Mockler T, Bryant D, HerreraEstrella A, Albert VA, Herrera-Estrella L. 2013. Architecture and evolution of a minute plant genome. Nature 498:94-98. DOI: 10.1038/nature12132.

Jeffreys, A. J., Neumann, R., \& Wilson, V. 1990. Repeat unit sequence variation in minisatellites: a novel source of DNA polymorphism for studying variation and mutation by single molecule analysis. Cell 60(3): $473-485$. DOI: 10.1016/0092-8674(90)90598-9.

Jurka J, Kapitonov V V., Pavlicek A, Klonowski P, Kohany O, Walichiewicz J. 2005. Repbase Update, a database of eukaryotic repetitive elements. Cytogenetic and Genome Research 110:462-467. DOI: 10.1159/000084979.

Kimura M. 1980. A simple method for estimating evolutionary rates of base substitutions through comparative studies of nucleotide sequences. Journal of Molecular Evolution 16:111-120. DOI: 10.1007/BF01731581.

Koike A, Nakai K, Takagi T. 2002. The Origin and Evolution of Eukaryotic Protein Kinases. Genome Letters 1:83104. DOI: $10.1166 / \mathrm{gl} .2002 .010$.

Koonin E V., Csuros M, Rogozin IB. 2013. Whence genes in pieces: Reconstruction of the exon-intron gene structures of the last eukaryotic common ancestor and other ancestral eukaryotes. Wiley Interdisciplinary Reviews: RNA 4:93-105. DOI: 10.1002/wrna.1143.

Kurtz S. 2003. The Vmatch large scale sequence analysis software. Ref Type: Computer Program.

Li F, Fan G, Lu C, Xiao G, Zou C, Kohel RJ, Ma Z, Shang H, Ma X, Wu J, Liang X, Huang G, Percy RG, Liu K, Yang W, Chen W, Du X, Shi C, Yuan Y, Ye W, Liu X, Zhang X, Liu W, Wei H, Wei S, Huang G, Zhang X, Zhu S, Zhang H, Sun F, Wang X, Liang J, Wang J, He Q, Huang L, Wang J, Cui J, Song G, Wang K, Xu X, Yu JZ, Zhu Y, Yu S. 2015. Genome sequence of cultivated Upland cotton (Gossypium hirsutum TM-1)

Peer) reviewing PDF | (2019:06:38434:3:0:NEW 11 Nov 2019) 
provides insights into genome evolution. Nature Biotechnology 33:524-530. DOI: 10.1038/nbt.3208.

388

389

390

391

392

393

394

395

396

397

398

399

400

401

402

403

404

405

406

407

408

409

410

411

412

413

414

415

416

417

418

419

420

421

422

423

424
Li F, Fan G, Wang K, Sun F, Yuan Y, Song G, Li Q, Ma Z, Lu C, Zou C, Chen W, Liang X, Shang H, Liu W, Shi C, Xiao G, Gou C, Ye W, Xu X, Zhang X, Wei H, Li Z, Zhang G, Wang J, Liu K, Kohel RJ, Percy RG, Yu JZ, Zhu YX, Wang J, Yu S. 2014. Genome sequence of the cultivated cotton gossypium arboreum. Nature Genetics 46:567-572. DOI: 10.1038/ng.2987.

Liu Z, Liu Y, Liu F, Zhang S, Wang X, Lu Q, Wang K, Zhang B, Peng R. 2018. Genome-wide survey and comparative analysis of long terminal repeat (LTR) retrotransposon families in four gossypium species. Scientific Reports 8. DOI: 10.1038/s41598-018-27589-6.

Liu Y, Peng R, Liu F, Wang X, Cui X, Zhou Z, Wang C, Cai X, Wang Y, Lin Z, Wang K. 2016. A Gossypium BAC clone contains key repeat components distinguishing sub-genome of allotetraploidy cottons. Molecular Cytogenetics 9. DOI: 10.1186/s13039-016-0235-y.

Liu X, Zhao B, Zheng HJ, Hu Y, Lu G, Yang CQ, Chen JD, Chen JJ, Chen DY, Zhang L, Zhou Y, Wang LJ, Guo WZ, Bai YL, Ruan JX, Shangguan XX, Mao YB, Shan CM, Jiang JP, Zhu YQ, Jin L, Kang H, Chen ST, He XL, Wang R, Wang YZ, Chen J, Wang LJ, Yu ST, Wang BY, Wei J, Song SC, Lu XY, Gao ZC, Gu WY, Deng X, Ma D, Wang S, Liang WH, Fang L, Cai CP, Zhu XF, Zhou BL, Chen ZJ, Xu SH, Zhang YG, Wang SY, Zhang TZ, Zhao GP, Chen XY. 2015. Gossypium barbadense genome sequence provides insight into the evolution of extra-long staple fiber and specialized metabolites. Scientific Reports 5. DOI: 10.1038/srep14139.

Lu H, Cui X, Liu Z, Liu Y, Wang X, Zhou Z, Cai X, Zhang Z, Guo X, Hua J, Ma Z, Wang X, Zhang J, Zhang H, Liu F, Wang K. 2018. Discovery and annotation of a novel transposable element family in Gossypium. $B M C$ Plant Biology 18. DOI: 10.1186/s12870-018-1519-7.

Ma J, Bennetzen JL. 2004. Rapid recent growth and divergence of rice nuclear genomes. Proceedings of the National Academy of Sciences 101:12404-12410. DOI: 10.1073/pnas.0403715101.

Marchler-Bauer A, Bo Y, Han L, He J, Lanczycki CJ, Lu S, Chitsaz F, Derbyshire MK, Geer RC, Gonzales NR, Gwadz M, Hurwitz DI, Lu F, Marchler GH, Song JS, Thanki N, Wang Z, Yamashita RA, Zhang D, Zheng C, Geer LY, Bryant SH. 2017. CDD/SPARCLE: Functional classification of proteins via subfamily domain architectures. Nucleic Acids Research 45:D200-D203. DOI: 10.1093/nar/gkw1129.

McCLINTOCK B. 1950. The origin and behavior of mutable loci in maize. Proceedings of the National Academy of Sciences of the United States of America 36:344-55.

Morgante M. 2006. Plant genome organisation and diversity: the year of the junk! Current Opinion in Biotechnology 17:168-173. DOI: 10.1016/j.copbio.2006.03.001.

Munoz-Lopez M, Garcia-Perez J. 2010. DNA Transposons: Nature and Applications in Genomics. Current Genomics 11:115-128. DOI: 10.2174/138920210790886871.

Okonechnikov, K., O. Golosova, M. Fursov and U. Team (2012). "Unipro UGENE: a unified bioinformatics toolkit." Bioinformatics 28(8): 1166-1167. DOI: 10.1093/bioinformatics/bts091.

Paterson AH, Wendel JF, Gundlach H, Guo H, Jenkins J, Jin D, Llewellyn D, Showmaker KC, Shu S, Udall J, Yoo MJ, Byers R, Chen W, Doron-Faigenboim A, Duke M V., Gong L, Grimwood J, Grover C, Grupp K, Hu G, Lee TH, Li J, Lin L, Liu T, Marler BS, Page JT, Roberts AW, Romanel E, Sanders WS, Szadkowski E, Tan X, Tang H, Xu C, Wang J, Wang Z, Zhang D, Zhang L, Ashrafi H, Bedon F, Bowers JE, Brubaker CL, Chee PW,

Peer) reviewing PDF | (2019:06:38434:3:0:NEW 11 Nov 2019) 
425

426

427

428

429

430

431

432

433

434

435

436

437

438

439

440

441

442

443

444

445

446

447

448

449

450

451

452

453

454

455

456

457

458

459

460

461

462

Das S, Gingle AR, Haigler CH, Harker D, Hoffmann L V., Hovav R, Jones DC, Lemke C, Mansoor S, Rahman MU, Rainville LN, Rambani A, Reddy UK, Rong JK, Saranga Y, Scheffler BE, Scheffler JA, Stelly DM, Triplett BA, Van Deynze A, Vaslin MFS, Waghmare VN, Walford SA, Wright RJ, Zaki EA, Zhang T, Dennis ES, Mayer KFX, Peterson DG, Rokhsar DS, Wang X, Schmutz J. 2012. Repeated polyploidization of Gossypium genomes and the evolution of spinnable cotton fibres. Nature 492:423-427. DOI: 10.1038 /nature 11798.

Piegu B, Guyot R, Picault N, Roulin A, Saniyal A, Kim H, Collura K, Brar DS, Jackson S, Wing RA, Panaud O. 2006. Doubling genome size without polyploidization: Dynamics of retrotransposition-driven genomic expansions in Oryza australiensis, a wild relative of rice. Genome Research 16:1262-1269. DOI: $10.1101 /$ gr.5290206.

R Core Team. 2014. R Language Definition V. 3.1.1. https://www.r-project.org/:Accessed Nov 2015.

Sanmiguel P, Bennetzen JL. 1998. Evidence that a recent increase in maize genome size was caused by the massive amplification of intergene retrotransposons. Annals of Botany 82:37-44. DOI: 10.1006/anbo.1998.0746.

Saranga Y. 2007. Special Issue: A century of wheat research - from wild emmer discovery to genome analysis. Israel Journal of Plant Sciences 55:207-313.

Senchina DS, Alvarez I, Cronn RC, Liu B, Rong J, Noyes RD, Paterson AH, Wing RA, Wilkins TA, Wendel JF. 2003. Rate variation among nuclear genes and the age of polyploidy in Gossypium. Molecular Biology and Evolution 20:633-643. DOI: 10.1093/molbev/msg065.

Treangen TJ, Salzberg SL. 2012. Repetitive DNA and next-generation sequencing: Computational challenges and solutions. Nature Reviews Genetics 13:36-46. DOI: 10.1038/nrg3117.

Wang K, Guo W, Zhang T. 2007. Detection and mapping of homologous and homoeologous segments in homoeologous groups of allotetraploid cotton by BAC-FISH. BMC Genomics 8. DOI: 10.1186/1471-2164-8178.

Wang K, Huang G, Zhu Y. 2016. Transposable elements play an important role during cotton genome evolution and fiber cell development. Science China Life Sciences 59:112-121. DOI: 10.1007/s11427-015-4928-y.

Wang M, Tu L, Yuan D, Zhu D, Shen C, Li J, Liu F, Pei L, Wang P, Zhao G, Ye Z, Huang H, Yan F, Ma Y, Zhang L, Liu M, You J, Yang Y, Liu Z, Huang F, Li B, Qiu P, Zhang Q, Zhu L, Jin S, Yang X, Min L, Li G, Chen LL, Zheng H, Lindsey K, Lin Z, Udall JA, Zhang X. 2019. Reference genome sequences of two cultivated allotetraploid cottons, Gossypium hirsutum and Gossypium barbadense. Nature Genetics 51:224-229. DOI: 10.1038/s41588-018-0282-x.

Wang K, Wang Z, Li F, Ye W, Wang J, Song G, Yue Z, Cong L, Shang H, Zhu S, Zou C, Li Q, Yuan Y, Lu C, Wei H, Gou C, Zheng Z, Yin Y, Zhang X, Liu K, Wang B, Song C, Shi N, Kohel RJ, Percy RG, Yu JZ, Zhu YX, Cang J, Yu S. 2012. The draft genome of a diploid cotton Gossypium raimondii. Nature Genetics 44:10981103. DOI: $10.1038 /$ ng.2371.

Wang KB, Wang WK, Wang CY, Song GL, Cui RX, Li SH, Zhang XD. 2001. [Studies of FISH and karyotype of Gossypium barbadense]. Yi chuan xue bao = Acta genetica Sinica 28:69-75.

WANG K, WENDEL JF, HUA J. 2018. Designations for individual genomes and chromosomes in Gossypium. Journal of Cotton Research 1. DOI: 10.1186/s42397-018-0002-1.

Peer) reviewing PDF | (2019:06:38434:3:0:NEW 11 Nov 2019) 
463

464

465

466

467

468

469

470

471

472

473

474

475

476

477

478

479

480

481

482

483

484

485

486

487

488

489

490

491

492

493

494

495

496

Wendel JF, Cronn RC. 2001. Polyploidy and the evolutionary history of cotton. Advances in Agronomy 78:139-186. DOI: 10.1016/S0065-2113(02)78004-8.

Wendel JF, Flagel LE, Adams KL. 2012. Jeans, genes, and genomes: Cotton as a model for studying polyploidy. In: Polyploidy and Genome Evolution. 181-207. DOI: 10.1007/978-3-642-31442-1_10.

Wessler SR. 2006. Transposable elements and the evolution of eukaryotic genomes. Proceedings of the National Academy of Sciences 103:17600-17601. DOI: 10.1073/pnas.0607612103.

Wicker T, Sabot F, Hua-Van A, Bennetzen JL, Capy P, Chalhoub B, Flavell A, Leroy P, Morgante M, Panaud O, Paux E, SanMiguel P, Schulman AH. 2007. A unified classification system for eukaryotic transposable elements. Nature Reviews Genetics 8:973-982. DOI: 10.1038/nrg2165.

Wickham, H. (2016). ggplot2: elegant graphics for data analysis, Springer.

Xie Y, Dong F, Hong D, Wan L, Liu P, Yang G. 2012. Exploiting comparative mapping among Brassica species to accelerate the physical delimitation of a genic male-sterile locus (BnRf) in Brassica napus. Theoretical and Applied Genetics 125:211-222. DOI: 10.1007/s00122-012-1826-6.

Yuan D, Tang Z, Wang M, Gao W, Tu L, Jin X, Chen L, He Y, Zhang L, Zhu L, Li Y, Liang Q, Lin Z, Yang X, Liu N, Jin S, Lei Y, Ding Y, Li G, Ruan X, Ruan Y, Zhang X. 2015. The genome sequence of Sea-Island cotton (Gossypium barbadense) provides insights into the allopolyploidization and development of superior spinnable fibres. Scientific Reports 5. DOI: 10.1038/srep17662.

Zhang T, Hu Y, Jiang W, Fang L, Guan X, Chen J, Zhang J, Saski CA, Scheffler BE, Stelly DM, Hulse-Kemp AM, Wan Q, Liu B, Liu C, Wang S, Pan M, Wang Y, Wang D, Ye W, Chang L, Zhang W, Song Q, Kirkbride RC, Chen X, Dennis E, Llewellyn DJ, Peterson DG, Thaxton P, Jones DC, Wang Q, Xu X, Zhang H, Wu H, Zhou L, Mei G, Chen S, Tian Y, Xiang D, Li X, Ding J, Zuo Q, Tao L, Liu Y, Li J, Lin Y, Hui Y, Cao Z, Cai C, Zhu X, Jiang Z, Zhou B, Guo W, Li R, Chen ZJ. 2015. Sequencing of allotetraploid cotton (Gossypium hirsutum L. acc. TM-1) provides a resource for fiber improvement. Nature Biotechnology 33:531-537. DOI: 10.1038/nbt.3207.

Zhang X, Tolzmann CA, Melcher M, Haas BJ, Gardner MJ, Smith JD, Feagin JE. 2011. Branch point identification and sequence requirements for intron splicing in plasmodium falciparum. Eukaryotic Cell 10:1422-1428. DOI: $10.1128 /$ EC.05193-11.

Zhao, X., Y. Ji, X. Ding, D. M. Stelly and A. H. J. P. m. b. Paterson (1998). "Macromolecular organization and genetic mapping of a rapidly evolving chromosome-specific tandem repeat family (B77) in cotton (Gossypium)." 38(6): 1031-1041. DOI: 10.1023/A:1006073116627.

Zhao, X. P., Y. Si, R. E. Hanson, C. F. Crane, H. J. Price, D. M. Stelly, J. F. Wendel and A. H. Paterson (1998). "Dispersed repetitive DNA has spread to new genomes since polyploid formation in cotton." Genome Research 8(5): 479-492. DOI: 10.1101/gr.8.5.479/Genome Res. 1998. 8: 479-492. 


\section{Table $\mathbf{1}$ (on next page)}

Plant materials used in this work, together with ploidy, studied genome, and specimen accession code. 
1 Table 1. Plant materials used in this work, together with ploidy, studied genome, and specimen accession 2 code.

\begin{tabular}{cccc}
\hline Species & Ploidy & Genome & Accession \\
\hline G. arboreum & $2 \mathrm{x}$ & $\mathrm{A}_{2}$ & Shixiya-1 \\
G. raimondii & $2 \mathrm{x}$ & $\mathrm{D}_{5}$ & $\mathrm{D} 5-07$ \\
G. hirsutum & $4 \mathrm{x}$ & $(\mathrm{AD})_{1}$ & CCRI-12 \\
G. barbadense & $4 \mathrm{x}$ & $(\mathrm{AD})_{2}$ & Xinhai-7 \\
\hline
\end{tabular}

3 
Table 2 (on next page)

Table 2. The distribution of ICRd motifs on different genome assemblies of tetraploid cotton. 
1 Table 2. The distribution of ICRd motifs on different genome assemblies of tetraploid cotton.

\begin{tabular}{cccc}
\hline Tetraploid & Version & Reference & ICRd motif \\
\hline $\begin{array}{c}\text { G. hirsutum } \\
(\text { AD) })_{1}\end{array}$ & BGI & (Li et al., 2015) & $\mathrm{D}_{\mathrm{h}} 01-\mathrm{D}_{\mathrm{h}} 13 ; \mathrm{A}_{\mathrm{h}} 02, \mathrm{~A}_{\mathrm{h}} 05, \mathrm{~A}_{\mathrm{h}} 07, \mathrm{~A}_{\mathrm{h}} 08$ \\
& NBI & (Zhang, Hu et al., 2015) & $\mathrm{D}_{\mathrm{h}} 01-\mathrm{D}_{\mathrm{h}} 13 ;$ None in A-sub \\
& HAU & (Wang, Tu et al., 2019) & $\mathrm{D}_{\mathrm{h}} 01-\mathrm{D}_{\mathrm{h}} 13 ;$ None in A-sub \\
& ZJU & (Hu, Chen et al., 2019) & $\mathrm{D}_{\mathrm{h}} 01-\mathrm{D}_{\mathrm{h}} 13 ;$ None in A-sub \\
$\begin{array}{c}\text { G. barbadense } \\
(\text { AD })_{2}\end{array}$ & CAS & (Liu et al., 2015) & $\mathrm{D}_{\mathrm{b}} 01-\mathrm{D}_{\mathrm{b}} 13 ;$ None in A-sub \\
& HAUv1 & (Yuan et al., 2015) & $\mathrm{D}_{\mathrm{b}} 01, \mathrm{D}_{\mathrm{b}} 02, \mathrm{D}_{\mathrm{b}} 06-\mathrm{D}_{\mathrm{b}} 09, \mathrm{D}_{\mathrm{b}} 12 ;$ None in A-sub \\
& HAUv2 & (Wang, Tu et al., 2019) & $\mathrm{D}_{\mathrm{h}} 01-\mathrm{D}_{\mathrm{h}} 13 ;$ None in A-sub \\
& ZJU & (Hu, Chen et al., 2019) & $\mathrm{D}_{\mathrm{h}} 01-\mathrm{D}_{\mathrm{h}} 13 ;$ None in A-sub \\
\hline
\end{tabular}

2 
Figure 1

The structure of ICRd motif

a: The self-blast of the ICRd motif showed the inner repeats; b: The structure of ICRd motif; c: The basic TR unit; $d$ : The examples of the structure illustration of the LTR-TEs inserted with ICRd motif. 
a

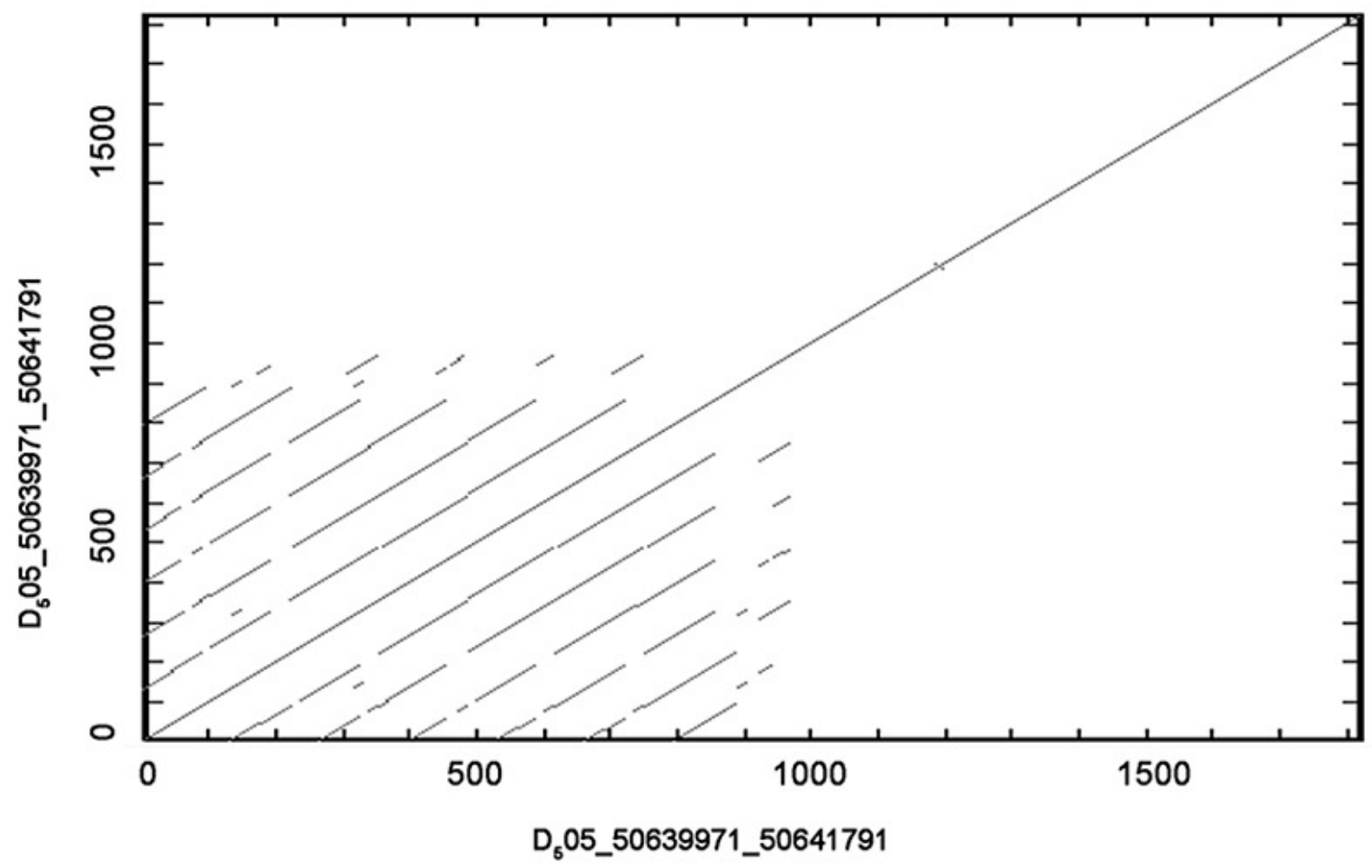

D GTAGAATTACTGGCTTCAATGTACTCCACTGCAACTTCATGGAGGTAAAATCCGCCATCTTCGATCTGCTCCACTACTGCTTAGGGAGACAAGACCTGAAATCTTCAACCTGCTCCACTGTCTCGAGGGA

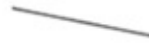

C ICRd motif
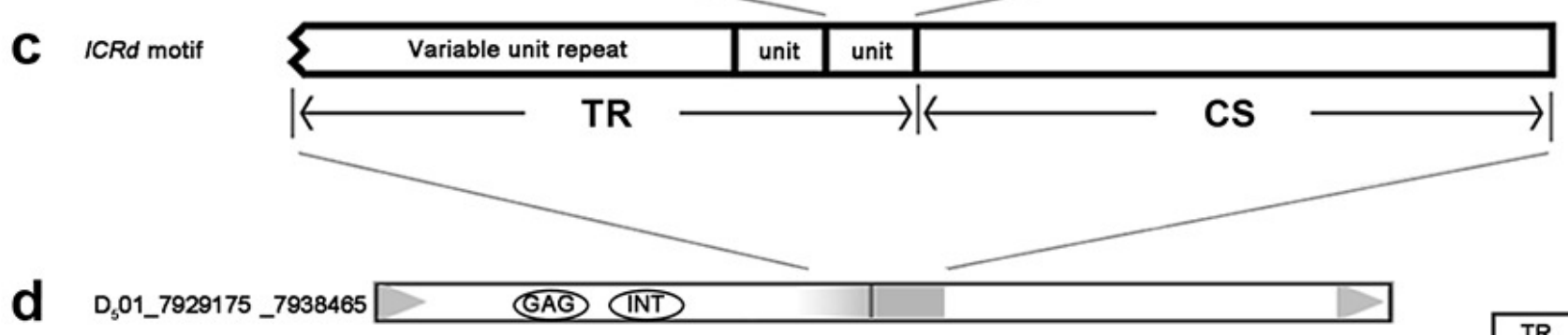

D 02 _14597849_14606769

(GAG) INT

1

$D_{5} 07 \_19182817 \_19192364$

GAG

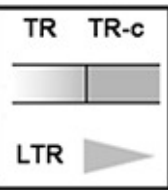

D $05 \_57995613 \_58007400$

(AP) GAG 
Figure 2

The content of the basic unit in the TRs

a: The basic unit content in the TRs involved in the ICRd motifs, displayed from small to large; b: The number of ICRd TRs that harboring different unit content, the $x$-axis adopt the intervals of unit content for convenient exhibition.
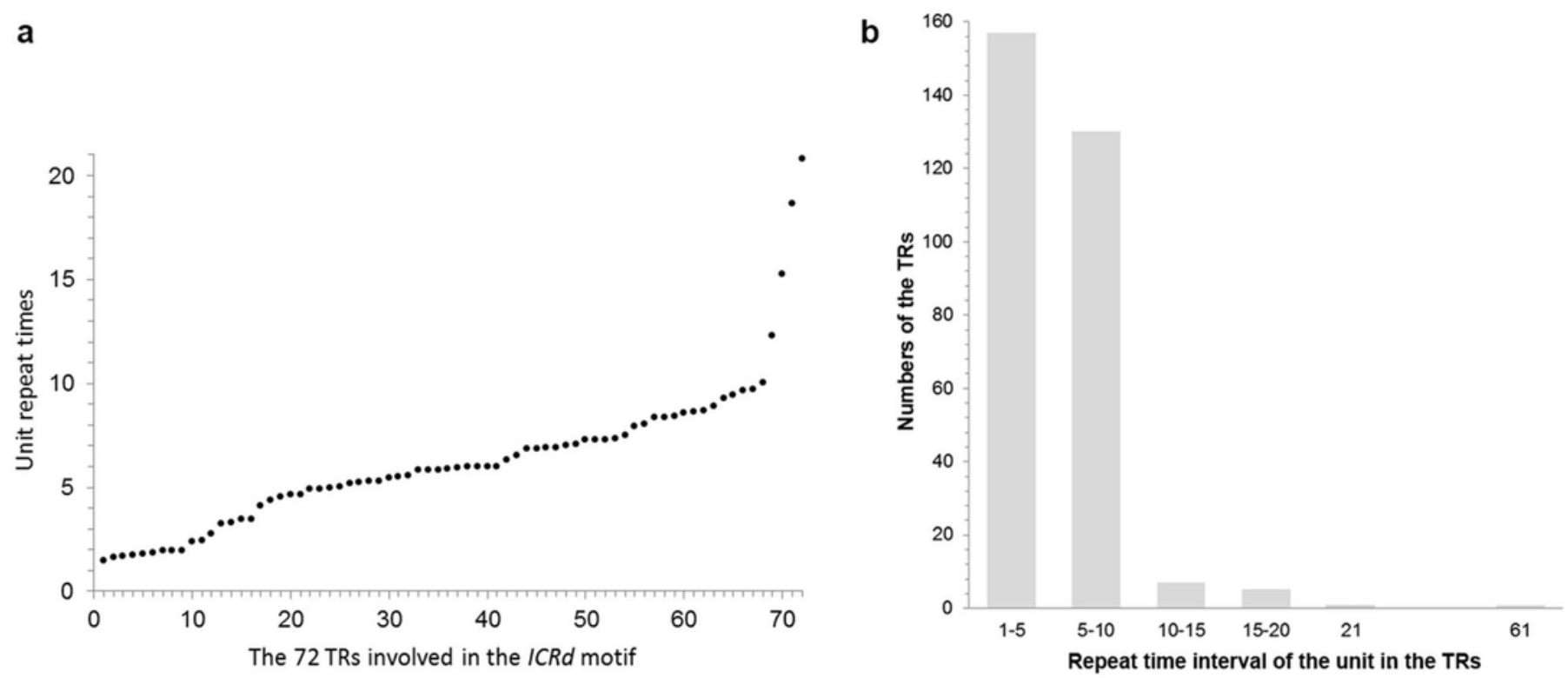
Figure 3

The FISH images of ICRd motif (red) hybridized to mitotic chromosomes of four species.

a: G. arboreum (AA); b: G. hirsutum (AADD); c: G. barbadense (AADD); d: G. raimondii (DD). Bar $=5 \mu \mathrm{m}$. 


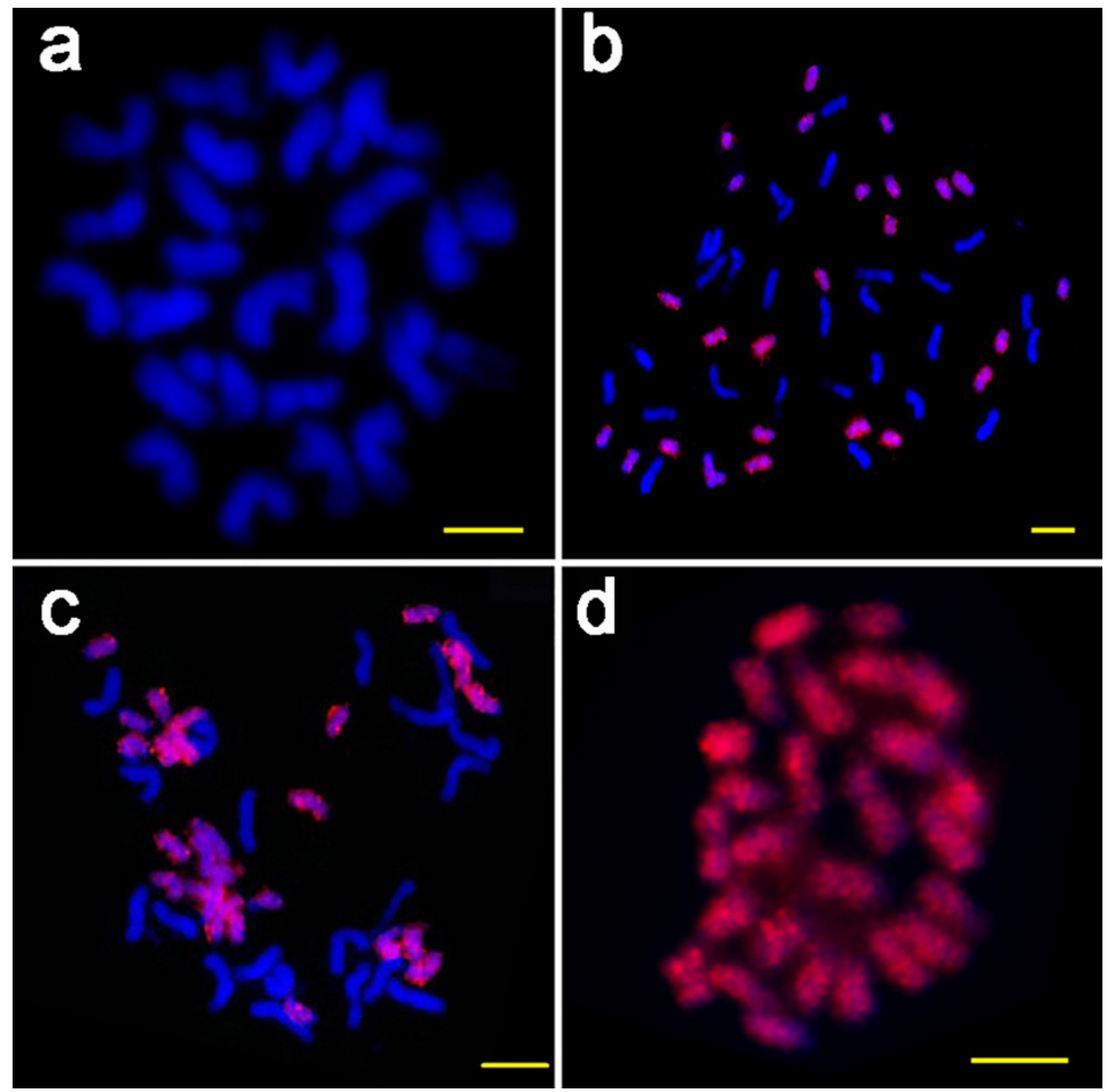


Figure 4

The consensus accumulation histogram from the whole alignment of the 72 LTR-TEs .

The region marked with the black line is the ICRd motif region.

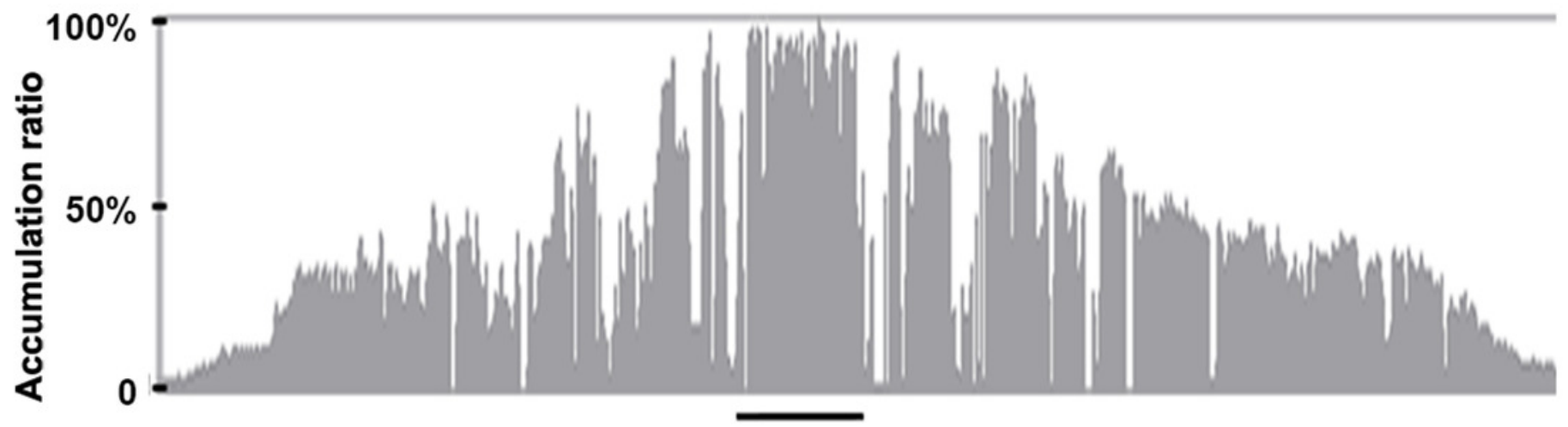

The consensus accumulation from the whole alignment of the 72 LTR-TEs 
Figure 5

The accumulation of putative active date of the LTR-TEs.

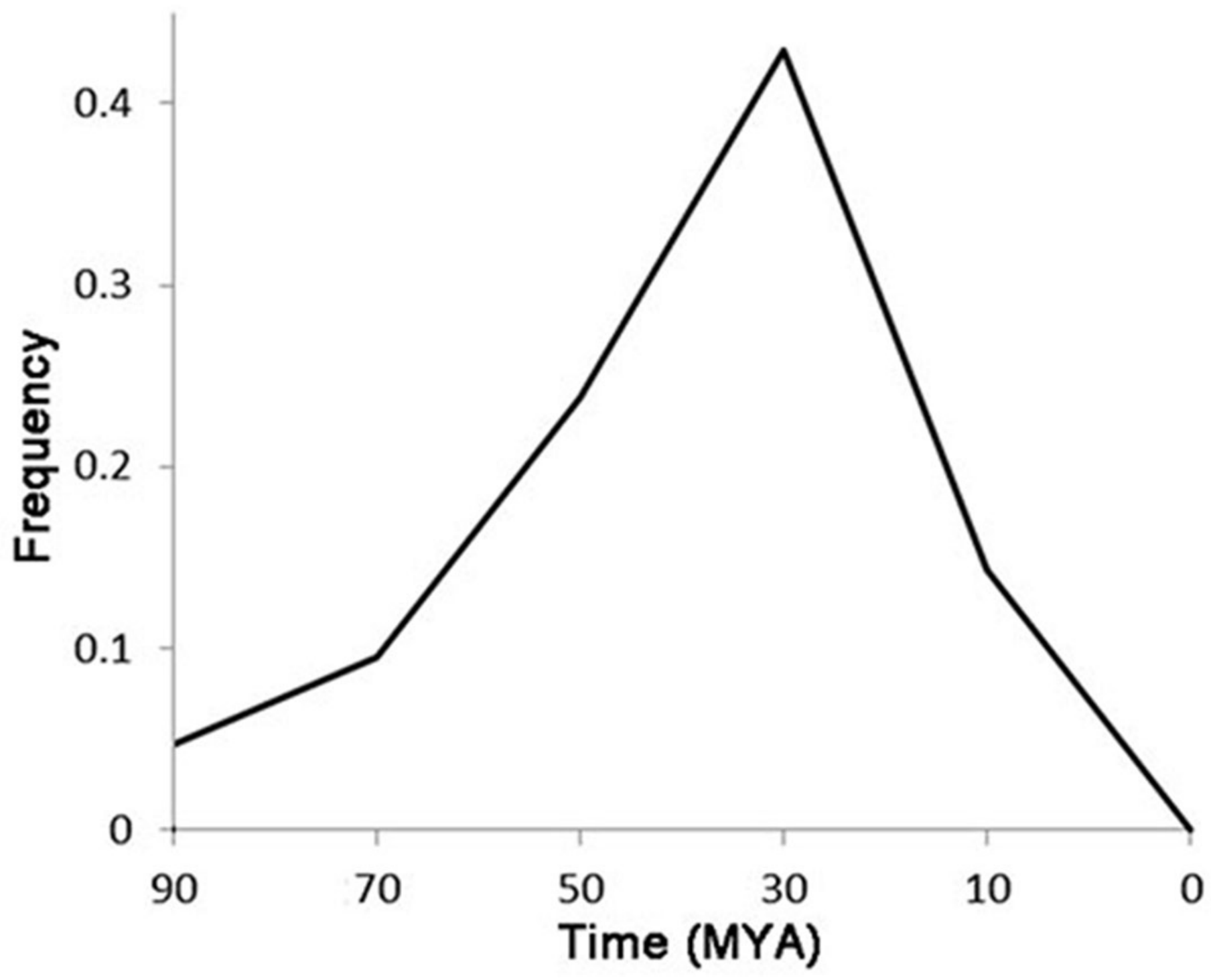




\section{Figure 6}

The distribution of the ICRd motif and its constituent in the $\mathrm{D}_{5}$ genome

a: Insertions of the ICRd motif and its constituents in the $\mathrm{D}_{5}$ genomes; b, c: ICRd TR and TR-C chromosomal distribution, the expected (grey) and actual (white) distributions across all chromosomes are illustrated; in addition, the density per megabase is shown for each chromosome. 
a

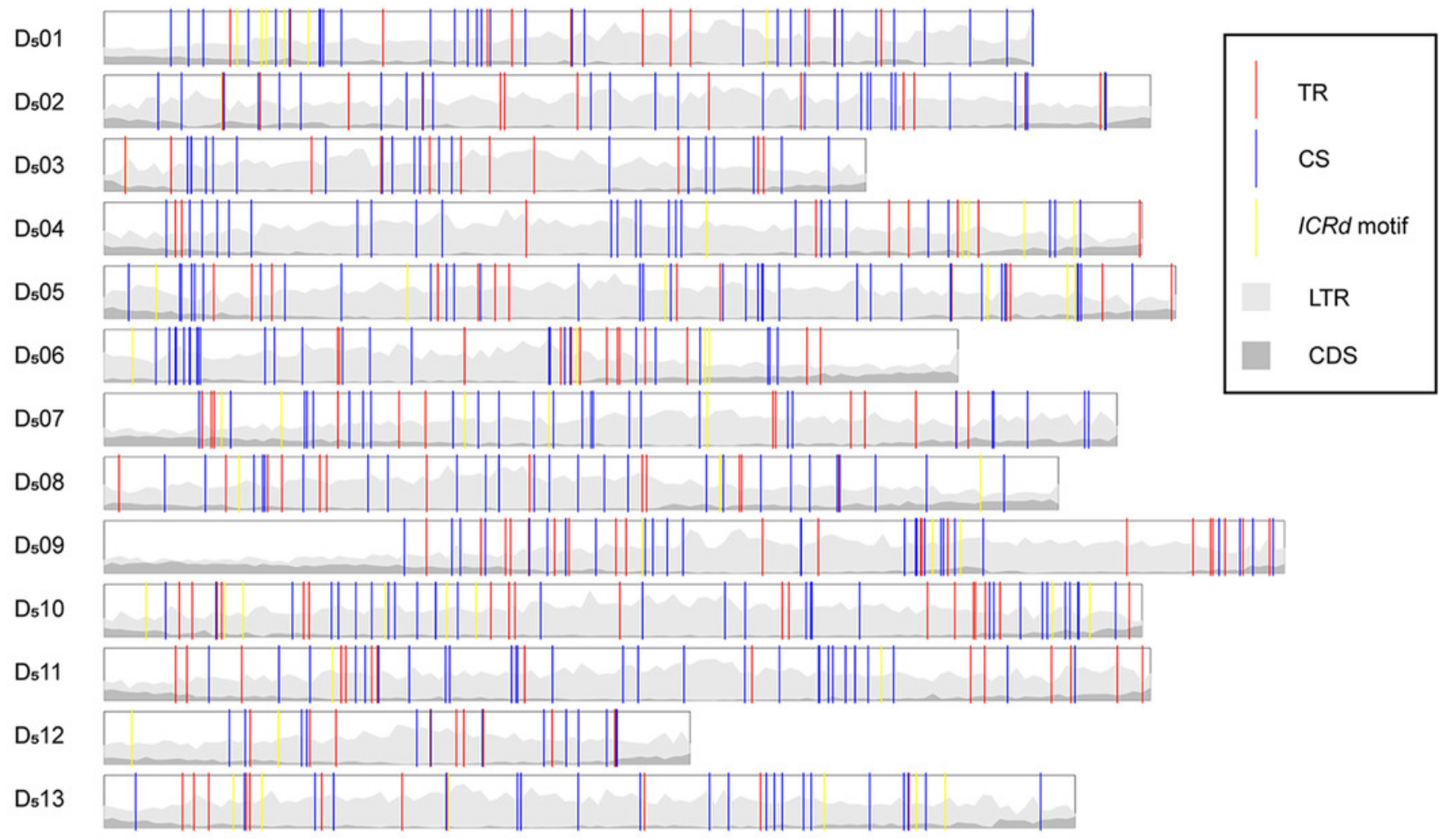

\begin{tabular}{llll}
\hline $0 \mathrm{e}+00$ & $2 \mathrm{e}+07$ & $4 \mathrm{e}+07$ & $6 \mathrm{e}+07$
\end{tabular}

b

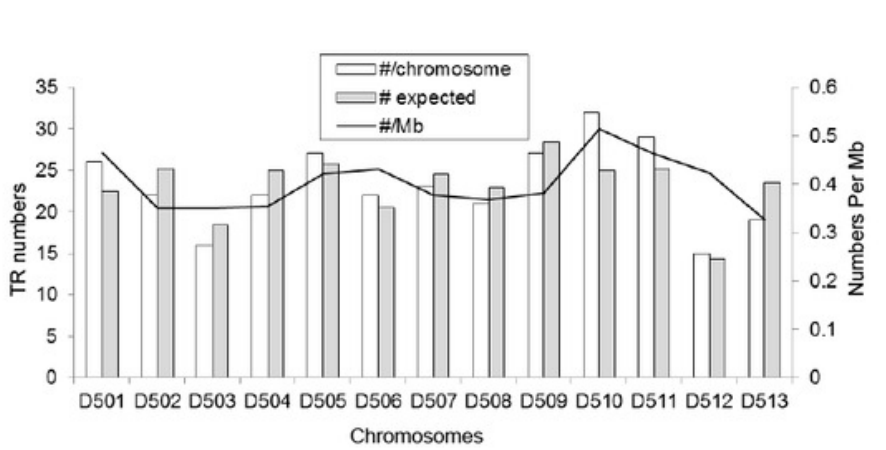

C

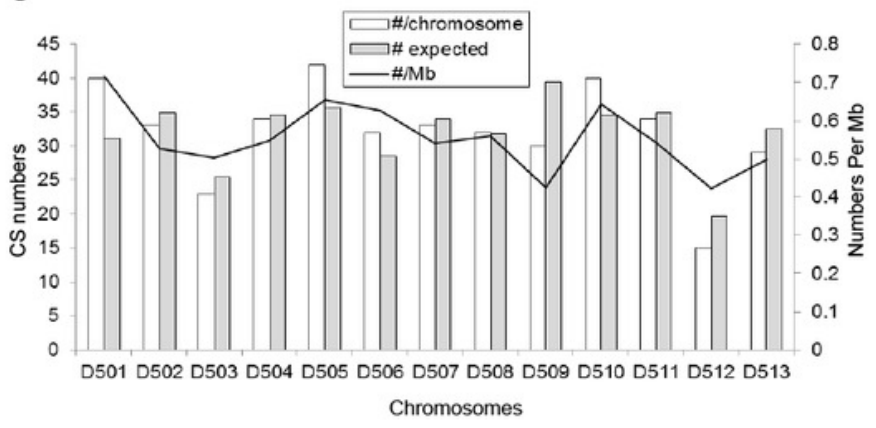


Figure 7

The colinearity of the two homologous segments.

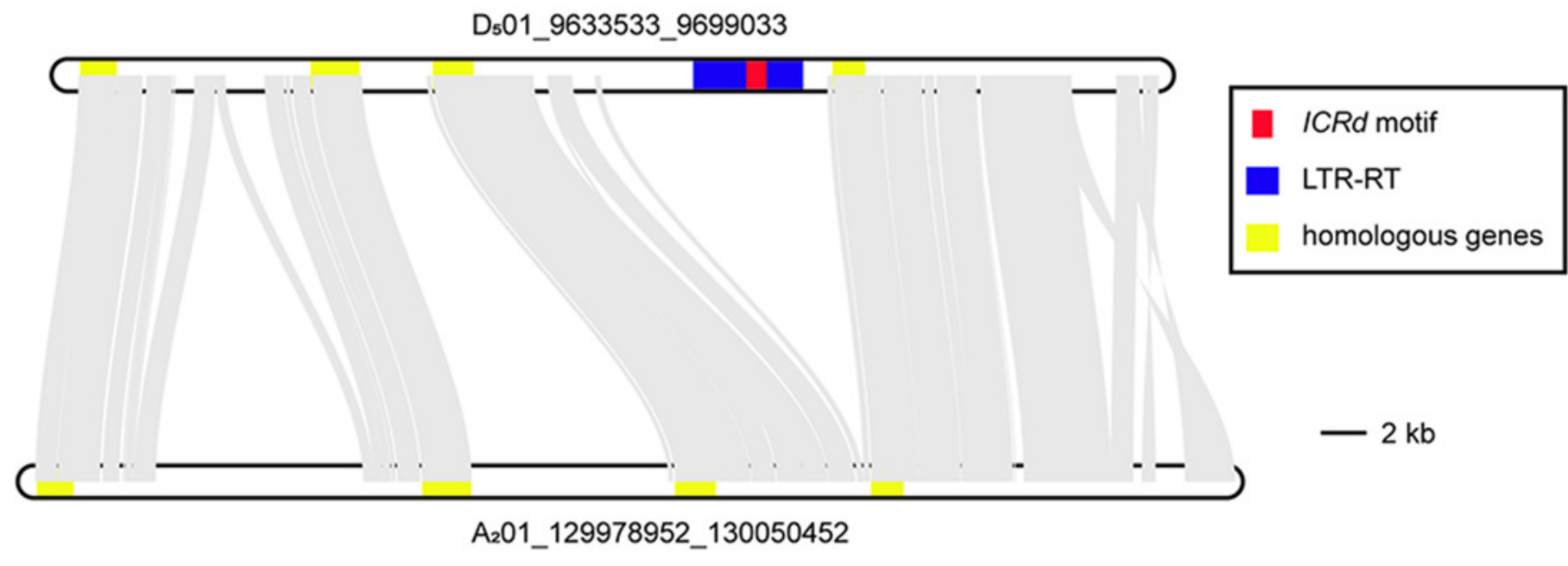

